\title{
Training Pediatric Scientists ${ }^{1}$
}

\author{
ROBERT P. KELCH AND ANTONIA C. NOVELLO
}

Department of Pediatrics [R.P.K.], University of Michigan Medical Center, Ann Arbor, Michigan 48109-0718 and National Institute of Child Health and Human Development, Bethesda, Maryland 20892

In common with the readership of Pediatric Research, we would like to further develop ways to ensure the continuation and expansion of excellent research by pediatric clinical scientists. We present our views on an extremely important challenge facing everyone who shares this goal. The challenge that we are referring to is how we can attract and adequately train a suitable number of pediatric scientists, pediatricians who not only possess excellent clinical skills but who also possess the necessary investigative skills and knowledge to apply the remarkable strengths of modern biology and technology to the developmental and health care needs of children.

The generic problem of dwindling and inadequate numbers of clinician-scientists has been emphasized by numerous scientific leaders, including Dr. James Wyngaarden, current director of the National Institutes of Health (NIH), and Dr. Joseph W. St. Geme, Jr., former Dean of the University of Colorado School of Medicine. In his 1979 report (1) "The Clinical Investigator as an Endangered Species," Dr. Wyngaarden pointed out that the number of serious physician-investigators had declined from 15,000 in 1968 to 8,000 in 1975 . In an editorial published posthumously, Dr. St. Geme (2) analyzed the clinician-scientist shortage critically and provided sage advice about how to meet the nation's needs. One of the approaches suggested by Dr. St. Geme, an approach that we heartily endorse, is to change pediatric subspecialty training from clinical apprenticeships to training programs for clinician-scientists. Dr. St. Geme stated that "The subspecialists we need should be educated to advance clinical biomedical science and the complex frontiers of fundamental clinical investigation." Dr. St. Geme also asked us this challenging question, "Do we have the tenacity to implement highly competitive research-oriented subspecialty fellowship programs?" As we hope to persuade you to accept, we believe that the answer to his question is yes.

Our affirmative response is based on three lines of evidence or observations which we will now review: 1) a detailed review of NIH funding for pediatric research and research training over the last decade; 2) the remarkable progress that has been made recently toward increasing the research orientation of fellowship training programs, and 3) the adoption of research-oriented fellowship training guidelines by the Association of Medical School Pediatric Department Chairmen (AMSPDC, Inc.). In preparation for the 1988 Society for Pediatric Research (SPR) presidential address, we gathered and reviewed detailed information about NIH funding for pediatric research and, in particular, research training. Analysis of these data reveals that in general pediatric scientists have fared relatively well, but there appear to be several missed opportunities that deserve our careful attention.

Tables 1-4 list the number of awards and award funding rates for the last 10 fiscal years by type of award: RO1 traditional research projects; $R 23$ research awards for new investigators, and R29 first independent research support and transition awards

Correspondence Robert P. Kelch, M.D., Department of Pediatrics, C. S. Mot Children's Hospital, Box 0718, D3202, Ann Arbor, MI 48109.

'Adapted from Dr. Kelch's Presidential Address to the Meeting of the Society for Pediatric Research, May 5, 1988, Washington, DC.
(FIRST); T32 institutional national research service awards (NRSA) for predoctoral and postdoctoral training; and F32 individual national research service awards for postdoctoral training (NRSA). On average, 4848 ROI awards have been granted per year and medical schools have received slightly more than half (Table 1). Awards per year ranged from a low of 4417 in 1980 to a high of 5559 in the previous year. The annual percentage of approved RO1 awards that were funded averaged $39 \%$ for medical schools as well as all domestic research institutions. The overall RO1 funding rate has varied between 34 and $51 \%$, but during the last 5 years it has varied only slightly, between 34 and $38 \%$.

Comparison of annual NIH award rates for all domestic institutions and medical schools by type of award reveals that the award rates for medical schools have been almost identical to the award rates for all domestic research-oriented institutions (Tables 1-4). Indeed, the greatest difference has been only $1 \%$ for the T32 type of award. Thus, medical schools account for slightly more than half of NIH's extramural research, and their success is no better or worse than domestic institutions in general. With these background comparisons in mind, we will now turn to a discussion of pediatric research and training awards and funding rates.

Although 92 pediatric medical school departments received some NIH funding for research and/or research training in 1987, the vast majority of funding was and remains concentrated in a relatively small number of research centers. Indeed, the top 20 departments received $64.7 \%$ of the total, and the top 30 departments received $82 \%$ of the funds awarded to departments of pediatrics. However, a significant amount of pediatric research and research training is carried out in administratively distinct children's hospitals. Because of the important role of researchoriented children's hospitals, we have chosen to combine the data for pediatric departments and children's hospitals in the columns labeled "Pediatrics" (Tables 1-4). "Pediatrics" award rates were calculated as a weighted average of the annual award rates of departments of pediatrics and children's hospitals. However, a few comments about the differences between average funding rates for departments of pediatrics and children's hospitals are in order.

On average, children's hospitals have received slightly more than one-third of all NIH awards made for pediatric research and research training. In addition, the overall funding rate of applications from children's hospitals has been 5\% more-39 versus $34 \%$. The greatest difference in annual funding rates is in the F32 category: children's hospitals have a remarkable funding rate of $57 \%$, whereas departments of pediatrics have averaged $41 \%$.

Figure 1 compares funding rates for medical schools with "Pediatrics" funding rates. It should be kept in mind that medical school funding rates are nearly identical to the funding rates for all domestic institutions. Because of the lack of exactly comparable data bases, we have chosen not to compare "Pediatrics" funding rates directly with those of other clinical disciplines, but we have included the funding rates for departments of internal medicine as an additional reference point (Tables 1-4). The 
Table 1. Awards and award rates (\%) for NIH competing ROI research projects

\begin{tabular}{|c|c|c|c|c|c|c|c|c|c|c|c|c|}
\hline \multirow[b]{2}{*}{$\mathrm{Y}$} & \multicolumn{2}{|c|}{$\begin{array}{l}\text { Domestic } \\
\text { institutions }\end{array}$} & \multicolumn{2}{|c|}{ Medical schools } & \multicolumn{2}{|c|}{$\begin{array}{l}\text { Medicine } \\
\text { departments }\end{array}$} & \multicolumn{2}{|c|}{$\begin{array}{c}\text { Pediatric } \\
\text { departments }\end{array}$} & \multicolumn{2}{|c|}{$\begin{array}{l}\text { Children's } \\
\text { hospitals }\end{array}$} & \multicolumn{2}{|c|}{ "Pediatrics" } \\
\hline & Awards & $\%$ & Awards & $\%$ & Awards & $\%$ & Awards & $\%$ & Awards & $\%$ & Awards & $\% *$ \\
\hline 1978 & 4840 & 45.1 & 2478 & 45.0 & 469 & 41.7 & 102 & 40.2 & 48 & 35.3 & 150 & 38.5 \\
\hline 1979 & 5559 & 51.3 & 2806 & 51.7 & 577 & 51.6 & 135 & 50.9 & 73 & 48.3 & 208 & 50.0 \\
\hline 1980 & 4417 & 41.7 & 2262 & 41.5 & 453 & 37.7 & 91 & 35.5 & 62 & 40.0 & 153 & 37.2 \\
\hline 1981 & 4604 & 38.5 & 2446 & 38.8 & 478 & 38.4 & 97 & 30.7 & 53 & 36.6 & 150 & 32.5 \\
\hline 1982 & 4483 & 34.2 & 2311 & 34.0 & 471 & 34.2 & 87 & 22.8 & 47 & 27.6 & 134 & 24.3 \\
\hline 1983 & 4727 & 36.2 & 2447 & 36.0 & 557 & 36.5 & 101 & 25.7 & 72 & 39.8 & 173 & 30.1 \\
\hline 1984 & 4688 & 36.0 & 2520 & 36.5 & 525 & 35.2 & 118 & 31.1 & 65 & 36.3 & 183 & 32.8 \\
\hline 1985 & 5212 & 35.7 & 2729 & 35.0 & 574 & 34.6 & 126 & 31.0 & 76 & 38.0 & 202 & 33.3 \\
\hline 1986 & 4931 & 34.0 & 2595 & 34.1 & 535 & 32.0 & 115 & 28.1 & 63 & 33.0 & 178 & 29.7 \\
\hline 1987 & 5018 & 37.8 & 2678 & 38.4 & 591 & 38.2 & 157 & 36.6 & 56 & 36.6 & 213 & 36.6 \\
\hline Annual average & 4848 & 39.1 & 2527 & 39.1 & 523 & 38.0 & 113 & 33.3 & 62 & 37.2 & 174 & 34.5 \\
\hline
\end{tabular}

* Weighted average.

Table 2. Awards and award rates (\%) for NIH competing $R 23$ and $R 29$ research projects

\begin{tabular}{|c|c|c|c|c|c|c|c|c|c|c|c|c|}
\hline \multirow[b]{2}{*}{$\mathrm{Yr}$} & \multicolumn{2}{|c|}{$\begin{array}{c}\text { Domestic } \\
\text { institutions }\end{array}$} & \multicolumn{2}{|c|}{ Medical schools } & \multicolumn{2}{|c|}{$\begin{array}{c}\text { Medicine } \\
\text { departments }\end{array}$} & \multicolumn{2}{|c|}{$\begin{array}{c}\text { Pediatric } \\
\text { departments }\end{array}$} & \multicolumn{2}{|c|}{$\begin{array}{l}\text { Children's } \\
\text { hospitals }\end{array}$} & \multicolumn{2}{|c|}{ "Pediatrics" } \\
\hline & Awards & $\%$ & Awards & $\%$ & Awards & $\%$ & Awards & $\%$ & Awards & $\%$ & Awards & $\% *$ \\
\hline 1978 & 199 & 41.2 & 117 & 42.4 & 36 & 48.0 & 9 & 52.9 & 1 & 16.7 & 10 & 43.5 \\
\hline 1979 & 187 & 49.1 & 104 & 47.7 & 29 & 42.6 & 5 & 50.0 & 4 & 44.4 & 9 & 47.4 \\
\hline 1980 & 169 & 43.4 & 102 & 43.8 & 32 & 43.8 & 4 & 28.6 & 5 & 55.6 & 9 & 39.1 \\
\hline 1981 & 326 & 43.0 & 205 & 45.5 & 75 & 50.7 & 20 & 58.8 & 9 & 39.1 & 29 & 50.9 \\
\hline 1982 & 334 & 39.4 & 215 & 41.4 & 63 & 39.9 & 14 & 32.6 & 9 & 47.4 & 23 & 37.1 \\
\hline 1983 & 311 & 41.0 & 186 & 42.2 & 52 & 35.1 & 17 & 42.5 & 2 & 16.7 & 19 & 36.5 \\
\hline 1984 & 330 & 36.5 & 206 & 38.4 & 44 & 33.6 & 20 & 32.3 & 2 & 14.3 & 22 & 28.9 \\
\hline 1985 & 394 & 39.6 & 222 & 39.9 & 70 & 44.9 & 14 & 28.6 & 8 & 40.0 & 22 & 31.9 \\
\hline 1986 & 353 & 38.2 & 213 & 38.3 & 74 & 42.8 & 22 & 36.1 & 3 & 30.0 & 25 & 35.2 \\
\hline 1987 & 509 & 27.2 & 290 & 27.4 & 82 & 26.6 & 22 & 21.6 & 12 & 35.3 & 34 & 25.0 \\
\hline Annual average & 311 & 39.9 & 186 & 40.7 & 56 & 40.8 & 15 & 38.4 & 6 & 34.0 & 20 & 37.6 \\
\hline
\end{tabular}

* Weighted average.

Table 3. Awards and award rates (\%) for NIH competing T32 training grants

\begin{tabular}{|c|c|c|c|c|c|c|c|c|c|c|c|c|}
\hline \multirow[b]{2}{*}{ Yr } & \multicolumn{2}{|c|}{$\begin{array}{l}\text { Domestic } \\
\text { institutions }\end{array}$} & \multicolumn{2}{|c|}{ Medical schools } & \multicolumn{2}{|c|}{$\begin{array}{c}\text { Medicine } \\
\text { departments }\end{array}$} & \multicolumn{2}{|c|}{$\begin{array}{c}\text { Pediatric } \\
\text { departments }\end{array}$} & \multicolumn{2}{|c|}{$\begin{array}{l}\text { Children's } \\
\text { hospitals }\end{array}$} & \multicolumn{2}{|c|}{ "Pediatrics" } \\
\hline & Awards & $\%$ & Awards & $\%$ & Awards & $\%$ & Awards & $\%$ & Awards & $\%$ & Awards & $\% *$ \\
\hline 1978 & 335 & 68.8 & 226 & 70.4 & 89 & 78.1 & 5 & 83.3 & 2 & 40.0 & 7 & 63.6 \\
\hline 1979 & 178 & 53.8 & 109 & 55.9 & 31 & 57.4 & 10 & 76.9 & 3 & 50.0 & 13 & 68.4 \\
\hline 1980 & 392 & 72.3 & 255 & 72.9 & 106 & 84.8 & 12 & 80.0 & 3 & 75.0 & 15 & 78.9 \\
\hline 1981 & 168 & 56.6 & 101 & 54.6 & 40 & 58.0 & 5 & 50.0 & 2 & 66.7 & 7 & 53.8 \\
\hline 1982 & 234 & 62.9 & 156 & 63.2 & 58 & 70.7 & 10 & 62.5 & 3 & 60.0 & 13 & 61.9 \\
\hline 1983 & 293 & 75.7 & 209 & 78.6 & 76 & 88.4 & 5 & 55.6 & 2 & 100.0 & 7 & 63.6 \\
\hline 1984 & 179 & 58.1 & 121 & 63.0 & 42 & 68.9 & 6 & 42.9 & 4 & 66.7 & 10 & 50.0 \\
\hline 1985 & 374 & 69.3 & 249 & 70.1 & 95 & 74.8 & 9 & 64.3 & 4 & 80.0 & 13 & 68.4 \\
\hline 1986 & 164 & 46.9 & 108 & 47.4 & 39 & 47.0 & 9 & 52.9 & 1 & 25.0 & 10 & 47.6 \\
\hline 1987 & 267 & 65.3 & 169 & 63.5 & 50 & 61.0 & 12 & 70.6 & 4 & 80.0 & 16 & 73.0 \\
\hline Annual average & 258 & 63.0 & 170 & 64.0 & 63 & 68.9 & 8 & 63.9 & 3 & 64.3 & 11 & 62.9 \\
\hline
\end{tabular}

* Weighted average.

average annual funding rates of departments of internal medicine are nearly identical to medical school rates; the rates differ by less than $1 \%$ for all types of awards with only one exception. Departments of medicine have a $69 \%$ funding rate for T32 training grants compared with $64 \%$ for medical schools.

The "Pediatrics" funding rate is slightly less than the medical school rate for all types of grants. For the last 10 years, the overall difference has been $4.7 \%$; the greatest differences have been in the funding rates of $\mathrm{RO} 1$ grants and F32 awards. During the last 10 years, the overall annual "Pediatrics" funding rate has varied from approximately 28 to $51 \%$, but during the last 5 years it has varied only slightly (between 32 and $36 \%$ ).

Figure 2 displays the 10-year trends in funding rates for F32 grants and specifically compares medical school and "Pediatrics" rates. The medical school funding rate has averaged $48 \%$ for the last 10 years, but there has been a slow, steady decline. "Pediatrics" funding rates have declined less, and during the last 5 years have, on average, been slightly more than the medical school rate: 44.5 versus $43.2 \%$. However, these particular data do not illustrate our current problem, but Table 4 shows a review of the 
Table 4. Awards and award rates (\%) for NIH competing F32 fellowships

\begin{tabular}{|c|c|c|c|c|c|c|c|c|c|c|c|c|}
\hline \multirow[b]{2}{*}{$\mathrm{Yr}$} & \multicolumn{2}{|c|}{$\begin{array}{l}\text { Domestic } \\
\text { institutions }\end{array}$} & \multicolumn{2}{|c|}{ Medical schools } & \multicolumn{2}{|c|}{$\begin{array}{c}\text { Medicine } \\
\text { departments }\end{array}$} & \multicolumn{2}{|c|}{$\begin{array}{c}\text { Pediatric } \\
\text { departments }\end{array}$} & \multicolumn{2}{|c|}{$\begin{array}{l}\text { Children's } \\
\text { hospitals }\end{array}$} & \multicolumn{2}{|c|}{ "Pediatrics" } \\
\hline & Awards & $\%$ & Awards & $\%$ & Awards & $\%$ & Awards & $\%$ & Awards & $\%$ & Awards & $\% *$ \\
\hline 1978 & 1061 & 59.5 & 536 & 61.0 & 118 & 63.8 & 26 & 47.3 & 8 & 88.9 & 34 & 53.1 \\
\hline 1979 & 1125 & 62.4 & 523 & 64.1 & 109 & 57.4 & 21 & 51.2 & 8 & 88.9 & 29 & 58.0 \\
\hline 1980 & 794 & 50.6 & 385 & 50.8 & 92 & 54.4 & 18 & 43.9 & 8 & 44.4 & 26 & 44.1 \\
\hline 1981 & 628 & 39.1 & 298 & 39.0 & 69 & 42.6 & 8 & 22.2 & 5 & 41.7 & 13 & 27.1 \\
\hline 1982 & 777 & 47.5 & 385 & 49.8 & 103 & 54.5 & 13 & 41.9 & 9 & 42.9 & 22 & 42.3 \\
\hline 1983 & 792 & 49.5 & 366 & 49.5 & 105 & 54.1 & 20 & 44.4 & 8 & 42.1 & 28 & 43.8 \\
\hline 1984 & 705 & 42.1 & 341 & 40.9 & 87 & 39.5 & 11 & 45.8 & 8 & 50.0 & 19 & 47.5 \\
\hline 1985 & 928 & 47.9 & 436 & 48.8 & 103 & 50.5 & 14 & 37.8 & 15 & 57.7 & 29 & 46.0 \\
\hline 1986 & 574 & 29.9 & 268 & 30.0 & 75 & 32.9 & 16 & 45.7 & 4 & 57.1 & 20 & 47.6 \\
\hline 1987 & 882 & 47.9 & 395 & 46.6 & 97 & 45.3 & 8 & 27.6 & 9 & 56.3 & 17 & 37.8 \\
\hline Annual average & 827 & 47.6 & 393 & 48.1 & 96 & 49.5 & 16 & 40.8 & 8 & 57.0 & 24 & 44.7 \\
\hline
\end{tabular}

* Weighted average.

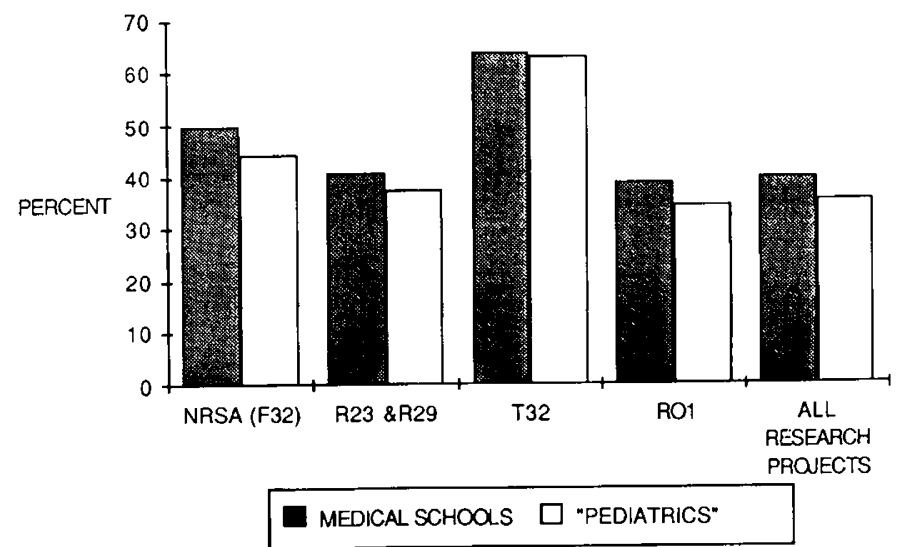

Fig. 1. Annual average 10-year NIH award rates for medical schools and "Pediatrics": 1978-1987.

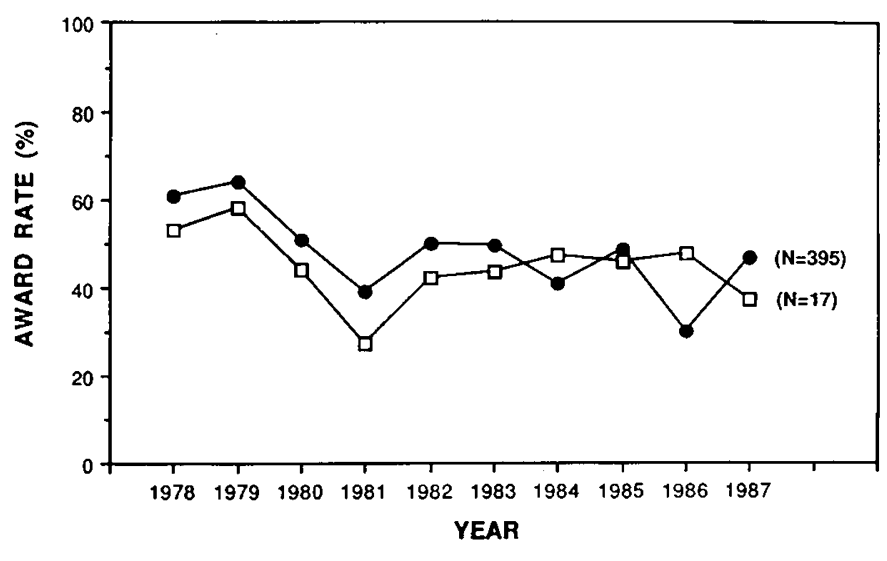

$\longrightarrow$ MEDICAL SCHOOLS - $\longrightarrow$ "PEDIATRICS"

Fig. 2. Comparison of medical school and "Pediatrics" individual NRSA (F32) funding rates: 1978-1987 (numbers in parentheses indicate total number of awards for fiscal year 1987).

actual number of F32 awards. On average, only 24 individual NRSA awards per year have been granted to "Pediatrics" programs, and in 1987 there were only 17: nine to children's hospitals and eight to departments of pediatrics. In contrast, in 1987, medical schools received 395 awards and departments of medicine received 97 awards. Why have we not encouraged, guided, and supported our trainees sufficiently to attract at least a proportionate share of F32 awards? Why were there only 47
F32 applications from children's hospitals and pediatric departments in 1987 ? Why did only 20 of the departments of pediatrics hold active F32 awards in 1987 ?

These questions and observations are particularly disturbing in view of several factors. Currently 45 to $50 \%$ of pediatric residents enter into subspecialty training. This means that at least 800 pediatricians enter into subspecialty training each year and that less than one of 16 must apply for individual NRSA awards. This not only is a poor record of participation but it also represents loss of a highly valuable educational experience for the vast majority of our trainees. Moreover, because the "Pediatrics" funding rate is actually very good, nearly $45 \%$ for the last 5 years, this likely represents a significant opportunity for funding our research trainees. Our trainees cannot succeed, however, if they do not apply.

Figure 3 continues our review of "Pediatrics" research funding rates by comparing rates for new investigator type awards, R23's and R29's, for medical schools and "Pediatrics." As is apparent, the funding rates have declined slowly during the last decade, and the "Pediatrics" funding rate has averaged approximately $3 \%$ less than the medical school rate. In this category, departments of pediatrics have competed somewhat better than children's hospitals: 38 versus $34 \%$. Once again, however, funding rates alone do not provide an accurate assessment of performance. In 1981, there was a striking increase in the number of R23 awards from approximately 10/year to 29. After the introduction of the FIRST Award R29, there has been a further increase to a total of 34 in 1987 . On average, nearly three-fourths of these awards are made to departments of pediatrics.

Pediatric RO1 research grant award rates are shown in Table 1. The total number of new "Pediatrics" RO1 awards has averaged 174 /year for the last 10 years; the least number, 134, was awarded in 1982; the largest number, 213, was awarded in 1987. Children's hospitals, on average, have received $35 \%$ of the total.

A comparative view of "Pediatrics" and medical school awards and award rates indicates that we have competed best for R23 and R29 awards and least well for individual NRSA awards. The remarkable difference in relative success rates is the result of a much lower application rate from pediatricians for F32 awards. For example, in 1987, departments of pediatrics accounted for $9.8 \%$ of medical schools' applications for R23 and R29 awards, but only $3.5 \%$ of individual NRSA applications.

We would like to emphasize several important points about NIH funding: 1) despite the misconceptions of some of our colleagues, pediatricians have fared reasonably well in the peer review process for NIH funding; 2) our greatest success, relatively speaking, has been in the attainment of new investigator type awards (R23 and R29); 3) pediatricians have competed least well for support for their research trainees, especially for individual NRSA awards; and 4) our trainees cannot succeed unless they 


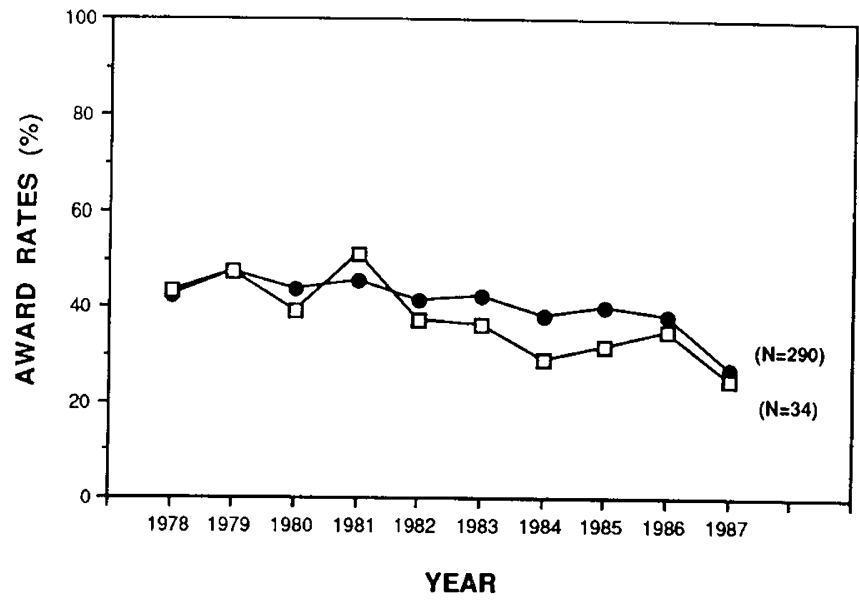

Fig. 3. Comparison of medical school and "Pediatrics" funding rates for R23 and R29 grants: 1978-1987 (numbers in parentheses indicate total number of awards for fiscal year 1987).

apply and they should not apply without our full vigorous support and guidance.

Before embarking on a review of recent developments that have affected and will greatly affect pediatric research training, perhaps it might be helpful to reflect on a well-known remark of Oliver Wendell Holmes, who reminded us that "The great thing in this world is not so much where we stand, as in what direction we are moving." We believe that considerable progress has been made toward the goal of ensuring an adequate supply of pediatric scientists for the future, and we will briefly review that progress in the following paragraphs.

After much debate and through the persuasive efforts of many individuals, the subspecialty committees of the American Board of Pediatrics have formally extended training requirements from 2 to 3 years. Rigorous accreditation processes for subspecialty training programs have been implemented by the appropriate review committees, and much greater emphasis has been placed on research accomplishments of both mentors and trainees in the accreditation and certification processes. Most likely, these steps will lead to a reduction in the number of training programs and the number of fellowship positions, but they should also enable us to concentrate our efforts and resources on the task at hand, the training of pediatric scientists.

Pediatric department chairmen, as a group, also have taken several important steps. Under the leadership of Dr. Fred Battaglia and with the strong support of many chairmen and scientific leaders, AMSPDC initiated the Pediatric Scientist Training Program, a program designed to attract our brightest residents and to prepare them to function as independent, productive investigators. At its recent meeting, AMSPDC took two additional steps. First, it decided to sponsor an annual "Frontiers in Science" program. This program will bring together pediatric chairs and their brightest residents in the 1 st or 2 nd year of pediatric training, trainees already in the Pediatric Scientist Training Program, and prominent pediatric scientists who will present overviews of their research. Second, AMSPDC unanimously adopted a set of fellowship training guidelines.

Based on the firm belief that the future of child health care, as well as the future of academic pediatrics, will depend greatly on scientific and technologic advances, AMSPDC has asserted that pediatricians should play major roles in the direction and application of the new advances, and in the allocation of society's resources toward unravelling the complexities of human development and human illnesses. With this assertion in mind, AMSPDC has stated that "The principal goal of fellowship training should be the development of future academic pediatri- cians." Attainment of this goal will require that excellent training become a major component of all fellowship training. Development of fellowship programs in this manner will greatly enhance clinical training because excellent clinical training requires a scholarly and scientifically inquisitive environment. Adequate clinical training in some subspecialties may require 2 years, and adequate research training often requires 3 years or longer; thus, up to 5 years of postresidency training will be necessary. Additional mechanisms must be developed to allow for the lengthy training programs necessary for success in the highly competitive, rapidly developing fields of developmental biology. Initiation of research training during medical school and residency years is an excellent way to begin to develop pediatric scientists. Also, appointment of advanced trainees as junior faculty members during their 4th and 5th years may be helpful, providing that they are allowed to spend $80 \%$ or more of their effort in supervised research and research training.

The specific guidelines adopted by AMSPDC are as follows:

1) Research training should begin as early as possible; premedical students, medical students, and pediatric residents should be strongly encouraged to participate in meaningful research and research activities should be carried out throughout fellowship training. Although it is difficult to precisely define adequate research training, it is highly unlikely that a trainees will compete successfully for peer-reviewed funding unless he or she has had the equivalent of at least 2 years of research training.

2) Applicants for fellowship training should be evaluated for their commitment to attainment of adequate research training and to a career in academic pediatrics. Previous accomplishments, such as involvement in research as a student or resident, attainment of a master's or doctoral (Ph.D.) degree, and publication of research manuscripts should be regarded highly.

3) Each fellow should have a mutually agreed upon scientific mentor. It is highly desirable, and some would say essential, for the mentor to be an established, funded, principal investigator capable of fostering the trainee's career development. If possible, a research advisory committee similar to the usual doctoral thesis committee should be established to further guide and assist the trainee. It is anticipated that many of the scientific mentors will be members of basic science departments.

4) All fellows should receive training in experimental design, statistical analysis, scientific writing, biomedical ethics, educational techniques, and preparation of grants for peer review. Fellows should be required to submit their research findings for publication in refereed journals by the end of their training, or soon thereafter. Preparation for peer-reviewed support for a portion of the research training should also be encouraged.

5) Strong linkages to basic and clinical science, public health, and behavioral science departments or programs should be developed by training program directors and pediatric chairs to enhance the opportunities for scholarship and the training of pediatric fellows.

6) Finally, and perhaps most importantly, graduates of regular and advanced training programs should be prepared to initiate independent research and to compete for peer-reviewed research funding.

In closing, we would like to propose a few challenges for members of the SPR and others who are interested in the future of pediatric research. First, we hope that the SPR will continue vigorously and actively to work toward the goal of making our fellowship programs function as training periods for pediatric investigators. In particular, we trust that members of the SPR, both individually and collectively, will embrace and support the AMSPDC fellowship training guidelines. We are confident that we can change behaviors and greatly alter the heavy clinical orientation of current fellowship programs, and in so doing, not only improve the future of pediatric research but also the future of the practice of general pediatrics. Second, the SPR should 
develop new ways to encourage and recognize research performed by "young or future investigators," and by that we mean medical students, residents, and fellows. Third and finally, we must join with our colleagues in other disciplines and continue to exert effective pressure to ensure that society allocates adequate resources not only for biomedical research but also for research training.

Acknowledgments. We would like to thank the staff members of the NICHD for compiling the raw data presented in this manuscript and the members of the AMSPDC research issues work group who helped to develop the fellowship training guidelines. We also gratefully acknowledge the analytical and technical assistance of Ms. Darlene Levenson and the fine secretarial assistance of Ms. Jean Wolter.

\section{REFERENCES}

1. Wyngaarden JB 1979 The clinical investigator as an endangered species. $\mathrm{N}$ Engl J Med 301:1254-1259

2. St. Geme JW Jr 1987 On science and subspecialism. J Pediatr 110:410-421 